Discussion Paper No. 13-091

\title{
Prospect Theory, Mitigation and Adaptation to Climate Change
}

Daniel Osberghaus

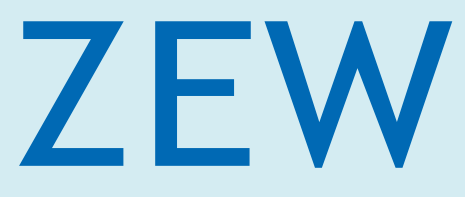

Zentrum für Europäische Wirtschaftsforschung $\mathrm{GmbH}$ Centre for European Economic Research 
Discussion Paper No. 13-091

\section{Prospect Theory, Mitigation and Adaptation to Climate Change}

Daniel Osberghaus

Download this ZEW Discussion Paper from our ftp server:

http://ftp.zew.de/pub/zew-docs/dp/dp13091.pdf

Die Discussion Papers dienen einer möglichst schnellen Verbreitung von neueren Forschungsarbeiten des ZEW. Die Beiträge liegen in alleiniger Verantwortung der Autoren und stellen nicht notwendigerweise die Meinung des ZEW dar.

Discussion Papers are intended to make results of ZEW research promptly available to other economists in order to encourage discussion and suggestions for revisions. The authors are solely responsible for the contents which do not necessarily represent the opinion of the ZEW. 


\title{
Prospect Theory, Mitigation and Adaptation to Climate Change
}

\author{
Daniel Osberghaus \\ Centre for European Economic Research (ZEW); L7, 1; 68161 Mannheim; Germany \\ osberghaus@zew.de
}

November 2013

\begin{abstract}
Climate change is one of the most pressing challenges in current environmental policy. Appropriate policies intended to stimulate efficient adaptation and mitigation should not exclusively rely on the assumption of the homo oeconomicus, but take advantage of well-researched alternative behavioural patterns. Prospect theory provides a number of climate-relevant insights, such as the notion that evaluations of outcomes are reference dependent, and the relevance of perceived certainty of outcomes. This paper systematically reviews what prospect theory can offer to analyse mitigation and adaptation. It is shown that accounting for reference dependence and certainty effects contributes to a better understanding of some well-known puzzles in the climate debate, including (but not limited to) the different uptake of mitigation and adaptation amongst individuals and nations, the role of technical vs. financial adaptation, and the apparent preference for hard protection measures in coastal adaptation. Finally, concrete possibilities for empirical research on these effects are proposed.
\end{abstract}

\section{Keywords}

Adaptation; Climate Change; Mitigation; Prospect Theory; Reference Point; Uncertainty

\section{Acknowledgements}

I would like to thank Klaus Eisenack, Leena Karrasch, Thomas Klenke, Anna Pechan, and Heinz Welsch from the University Oldenburg as well as Claudio Baccianti, Peter Heindl and Michael Schymura from the Centre for European Economic Research in Mannheim for useful comments and fruitful discussions.

\section{Introduction}

Mitigation of climate change as well as adaptation to its actual and expected effects is one of the largest challenges in current environmental policy. In order to design appropriate climate policies, a deep understanding of the decision processes related to mitigation and adaptation behaviour is indispensable. How do various actors respond to the effects of climate change and the incentives set by climate policies? For climate policy recommendations, most economists have used standard economic approaches based on the assumptions of the homo oeconomicus and rational decision 
making - although many scholars have argued that models from behavioural economics provide a more realistic description of observed behaviour in environmental issues (van den Bergh et al. 2000; Brekke and Johansson-Stenman 2008; Gowdy 2008; Gsottbauer and van den Bergh 2010; Shogren et al. 2010; Shogren and Taylor 2008; Venkatachalam 2008).

This paper joins the debate on behavioural economics in climate change mitigation and adaptation. In contrast to the existing literature, it focusses on prospect theory (PT) and compiles the implications of this widely-accepted theory on relevant decision problems in the climate arena in a systematic and detailed manner. Subsequently, concrete approaches on empirical applications of the theory are proposed. It will be demonstrated that PT has the potential to shed new light on some highly relevant economic puzzles in the climate arena, including (but not limited to) the following:

- The question why some actors prefer aggressive climate mitigation and adaptation, while others are more reluctant to climate-related action (Eisenack and Stecker 2012). Besides well-known factors like vulnerability, discounting, political and economic costs of action, it will be shown that PT can explain differences in the values ascribed to climate mitigation and adaptation activities by the framing of climate change. More concretely, those who perceive the current climate as the reference point tend to ascribe a higher value to climate action than those who have already shifted their reference point to the future climate. This and related effects will be further explored in section 3.1.

- The attractiveness of technical adaptation (e.g. technical flood protection measures) versus financial adaptation (e.g. purchase of flood insurance). Although insurance coverage is available, technical measures are used by a non-negligible share of households (Bichard and Kazmierczak 2012; Grothmann and Reusswig 2006). As an explanation for technical protection, the preservation hypothesis was formulated which considers the fact that human beings and personal belongings are protected by technical measures, but not by insurance (Carson et al. 2013). As will be discussed, PT opens a new perspective on the choice between technical and financial adaptation by assuming a certainty bonus for measures whose effects are perceived as certain over measures with effects perceived as uncertain (section 3.2).

- On another level, the certainty effect can also be helpful in the discussion on preferred strategies in coastal adaptation. In general, three broad strategies are available - retreat, accommodate and protect, whereby the latter may be divided into soft and hard protection. By date, it seems that most decision makers prefer hard protection (Meyer et al. 2012; Regierungskommission Klimaschutz 2012), although alternative and complementary options are repeatedly advocated by many scholars from different disciplines (Adger et al. 2005; Kundzewicz 2002; Pramova et al. 2012). Possible explanations for this discrepancy include reasons from the political economy sphere (building structural protection brings an immediate and local economic stimulus), or non-internalisation of external effects of some soft protection measures (environmental benefits of wetlands may be ignored in the costbenefit evaluation). In addition to these approaches, PT offers the possibility that hard protection strategies include a perceived certainty bonus which is absent in the alternatives (section 3.2). Although this example has some similarities with the abovementioned question of technical versus financial adaptation, there are important differences in terms of the decision level and alternative determinants. Moreover, PT introduces the isolation effect which can be utilised to illustrate the effects of different framings in these decisions (section $3.3)$. 
Although rarely focussed on PT, there is a strand of literature discussing the implications of behavioural economics on environmental policy. Brekke and Johansson-Stenman discuss PT, but they focus exclusively on the role of loss aversion for the appropriate discount rate for abatement projects (Brekke and Johansson-Stenman 2008, page 283-284). Loss aversion is also mentioned by other authors as a reason for the gap between willingness-to-pay and willingness-to-accept-compensation measures (Kahneman et al. 1990; Knetsch 2010). In the present paper, loss aversion is additionally discussed as a determinant of adaptation and mitigation relative to non-climate action. Gsottbauer and van den Bergh elaborate on the implications of bounded rationality on climate policy. As a finding related to PT, the authors highlight the role of risk perception for the uptake of insurance and other adaptation measures (Gsottbauer and van den Bergh 2010, page 289-290). In extension to this review, the present paper analyses the implications of PT for a much broader array of climate response measures ${ }^{1}$ - including some aspects of mitigation - and describes the underlying effects. Other sources discuss the implications of behavioural economics on environmental policy more generally (van den Bergh et al. 2000; Gowdy 2008; Shogren et al. 2010; Shogren and Taylor 2008; Venkatachalam 2008). Complementary to these works, this paper systematically identifies connections and empirical applications of PT on climate response measures. It will be shown that PT suggests potential determinants of observed adaptation and mitigation behaviour which have been broadly neglected so far, namely reference dependence and certainty perception.

A detailed introduction to the original PT version can be found in the works of Kahneman and Tversky (Kahneman and Tversky 1979; Tversky and Kahneman 1986). Later on it has been modified in order to avoid the violation of stochastic dominance and to extend it to the case of more than two nonzero outcomes ("Cumulative Prospect Theory" by Tversky and Kahneman 1992). For simplicity, this analysis is limited to the most basic and general findings of PT, which are differing from expected utility theory (EUT) - the conclusions, however, also hold under the more generalised versions. This article also does not join the debate on the consistence of PT and whether it is more valid than EUT or not (Birnbaum 2008; Harrison and Rutström 2009; Levy and Levy 2002). Instead, this contribution approaches the following question: If PT is a valid descriptive theory (for an individual or for a fraction of a population or for specific decisions), what will it imply for climate response measures?

Although a full introduction of PT will not be provided, some of the basic features and differences to EUT shall be mentioned. In general, PT differs from EUT by being an "unabashedly descriptive" theory without making normative claims (Tversky and Kahneman 1986, page 272). The overarching goal is to describe decisions under uncertainty as they are observed, in order to analyse the underlying decision making process. By avoiding normative claims and focussing on the descriptive power of the theory, PT is able to explain typical deviations from EUT (Kahneman and Tversky 1979). The decision making process, according to the authors, consists of two phases: First, the decision maker "organizes and reformulates the options so as to simplify subsequent evaluation and choice" (Kahneman and Tversky 1979, page 274). In this editing phase, outcomes are defined as gains and losses relative to a reference point. This is an important difference with the EUT: While EUT focuses on final wealth as the source of utility PT assumes that changes in wealth (gains and losses) are relevant for the value of an outcome. In the second phase, the evaluation phase, the edited options are evaluated according to their values (by a value function, dependent on gains, losses, and the

\footnotetext{
${ }^{1}$ In this paper, the term "response measure" refers to any private or public activity which is designed to either reduce greenhouse gas emissions (mitigation) or reduce the damage, given that climate change is occurring (adaptation to damages), or yielding the potential benefits of climate change (adaptation to benefits).
} 
reference point) and their decision weights (which are a function of stated probabilities, but contrary to EUT - not identical to them).

The main findings of PT which are relevant for the rest of this paper are the following:

a. The relevance of the reference point, tackling the question whether outcomes are evaluated as gains or losses;

b. The certainty effect, stating that the weight of certain outcomes is disproportionally high; ${ }^{2}$

c. The isolation effect as a special case of the certainty effect for decisions in intransparent and sequential decision problems.

Throughout the paper, references will be made to a stylised case in order to illustrate the practical relevance of the presented issues. Imagine a community located at a river delta in a high or middle income country. The area is exposed to sea level rise and river floods. In the area, a settlement and agricultural land is located. Let it be uncertain whether the existing dikes are sufficiently high under climate change conditions. The agricultural production may be affected negatively by floods and extreme weather events, but also a positive effect is possible due to better average vegetation circumstances. Several response measures (adaptation and mitigation) are available to the individual inhabitants, farms, the community and the respective nation. Assume that there are no institutional or social barriers or limits to response measures so that we can focus on the behavioural economics in the evaluation of alternatives. Most of the illustrative response measures described in the following sections are feasible within the scope of this stylised case.

The rest of the paper is structured as follows. The next section raises the question whether and under which conditions PT is applicable to climate change issues. In the third section, examples, where PT has the potential to contribute to a better understanding of observed adaptation and mitigation behaviour, are discussed. This includes also the abovementioned cases of climate-related vs. non-climate-related activities, technical vs. financial adaptation, and attractiveness of coastal adaptation strategies. In the fourth section, concrete possibilities for empirical applications in the climate change field are described in more detail. The last section summarises and concludes.

\section{Applicability of Prospect Theory on Climate Change}

As there is no specific work yet that deliberately focuses on the implications of prospect theory (PT) on climate change responses, the applicability of PT in the context of climate change must be clarified. There are several points which raise doubts about the legitimacy of PT in climate issues. PT was developed for the description of individual decisions under risk, and most of these decisions were met rather spontaneously. Furthermore, collective action is not an issue - the decision problems, at least in the experiments conducted by Kahneman and Tversky, were presented to isolated individuals. Obviously, climate change decisions are often extremely different from these settings. Large mitigation and adaptation projects are normally not evaluated by individuals, but by government bodies, boards of management, or other decision committees. Presumably, they do not meet their decisions spontaneously, but after a careful review of consequences and alternatives although "incidental adaptation" also exists (Eisenack and Stecker 2012). Finally, collective climate

\footnotetext{
${ }^{2}$ The certainty effect is a consequence of probability weighting near the endpoints (pronounced overweighting of very small but positive probabilities and pronounced underweighting of probabilities close but not equal to one) (Tversky and Kahneman 1992, page 316).
} 
policies such as the provision of public goods or the regulation of externalities involve considerations and decision processes which are very different from the personal evaluation of risky outcomes on the individual level. In a review of empirical applications of PT, topics are identified where works based on PT are still relatively rare, such as public finance and macroeconomics (Barberis 2013b, page 190). Arguably, one important reason is that decisions in these fields are often collective decisions.

However, this issue might deserve a closer look. Firstly, it is not the case that each and every mitigation and adaptation decision is a collective action. Private energy consumption, demand for climate-friendly everyday goods, choice of travel mode and tourist destination, and insurance demand are examples of individual climate response measures. So at least this class of climate responses is similar to the decision types analysed by the PT authors. Indeed, many of the climate responses discussed in the following sections are individual decisions.

Secondly and more fundamentally, it is a debatable question in how far collective decisions follow normatively consistent and socially optimal patterns (such as decisions grounded in EUT would do) or whether they should rather be oriented to the preferences of the individuals. Note that - at least in democracies - collective decisions are met on behalf of the voters, which are individuals for which the behavioural patterns described by PT may hold. A recent article on public adaptation highlights this point from a public choice perspective by stating that governments may intentionally over or underinvest in adaptation in order to meet observed or expected voters' preferences ("demand side of adaptation") (Gawel et al. 2012, page 9).

Note that there is empirical evidence suggesting that collective action sometimes is better described by PT than by EUT (Fanis 2004; Masters 2004). Rosenman et al. apply PT to the decision where to site a nuclear waste repository (Rosenman et al. 1988). Their conclusion is that PT is "applicable to environmental decision making where individual evaluations of risk are a key determinant of economic costs" (page 348). A general appeal for the applicability of PT in collective action based on evolutionary economics is published by Vis (Vis 2011). Although not focused on PT, other sources argue that government action may follow certain patterns of behavioural economics, including an overreaction to uncertainties (Carlsson and Johansson-Stenman 2012, page 92; McCaffery and Slemrod 2004, page 10; Shogren and Taylor 2008, page 31). A more critical standpoint towards the application of PT for collective action is taken by Levy who also highlights the methodological difficulties of such an approach (Levy 2003; Levy 1996). This debate is out of the scope of this paper; but in the light of the cited literature, it should not be ruled out that PT is applicable to collective decisions. Even if the application of PT on collective action was not accepted, recall that there are individual responses to climate change for which analyses in a PT framework are probably feasible.

Another point which raises doubts about PT in climate change is the nature of the underlying uncertainty. The original version of PT is based on the assumption of risky outcomes with known probabilities, but not on ambiguity which incurs uncertainty about the probabilities of uncertain events. The latter is undoubtedly more relevant for climate change (IPCC 2013; Kunreuther et al. 2013a; Millner et al. 2013). However, PT has been modified in order to tackle ambiguous decision problems as well (Tversky and Kahneman 1992). Moreover, several relevant insights of PT are independent of the knowledge of exact probabilities. For a first evaluation of uncertain options the mere information whether an outcome is impossible, certain, has a very low, a moderate, or a high probability is meaningful, as will be shown in the next section. The treatment of uncertainties in the 
report of the IPCC (IPCC 2013, page 2) shows that such an evaluation is indeed possible in climate change problems.

Other concerns with regard to the application of PT in climate issues refer to the general points of critique of the theory. As it is not the aim of this paper to discuss the general validity of PT, just one critical argument and the respective response of Tversky and Kahneman is mentioned here. Sceptics of PT highlighted the role of learning. After experiencing the consequences of their previous decisions in similar situations, individuals would adjust their behaviour (towards more EUT-like behaviour) in order to avoid identified errors. This effect is not doubted by proponents of PT, but the condition under which effective learning is possible deserves a closer look: "it requires accurate and immediate feedback about the relation between the situational conditions and the appropriate response" (Tversky and Kahneman 1986, page 274). The authors argue that this condition is rarely fulfilled, because: (a) feedbacks are often delayed and hence not clearly attributable to specific decisions; (b) the reliability of feedbacks decreases in a variable environment since decisions which were wrong in the past may be right now; (c) the counterexample is often missing; (d) some important decisions are unique and provide no opportunity for learning. Considering these reasons for insufficient feedbacks, an astonishing congruence with current discussions about climate change responses becomes apparent. ${ }^{3}$ One can speculate that Tversky and Kahneman would have used climate change as a prime example of their argumentation, if it had been on the agenda in the 1980s.

Finally, when applying PT to climate change, one has to be aware of the markedly descriptive nature of PT. This is in sharp contrast to many studies which try to define the optimal policy under uncertainty, thereby being prescriptive. As a consequence, one may not expect a decision model which yields some optimal solution. Instead, PT may provide insights in behavioural patterns which are relevant for climate response decisions. These insights could proof valuable for a prescriptive analysis, including policy recommendations. ${ }^{4}$ This is, however, a second step, which is not intended in this paper.

To conclude, there are no sufficient reasons to exclude the applicability of PT in climate change issues a priori, even though there are important points to be keenly aware of - such as the validity of PT in collective action decisions and its descriptive nature. On the other side, PT offers promising features for the analysis of climate change responses. The consideration of gains and losses instead of final wealth (reference dependence) and the unproportionally high decision weight of certain outcomes (certainty effect) seem particularly relevant for the evaluation of climate response measures, as will be pointed out in the following section.

\section{Insights from Prospect Theory for Climate Change Responses}

This section is structured along relevant findings of prospect theory (PT) which may give novel insights for the analysis of climate change responses. These are the reference dependence (the question whether outcomes are evaluated in the domain of gains or losses), the certainty effect (the

\footnotetext{
${ }^{3}$ This is not to say that learning is impossible under climate change (see e.g. the concept of "climate analogues" (Hallegatte et al. 2007)). It is, however, at least very difficult to evaluate consequences of climate response measures ex ante for exactly the reasons mentioned by the PT authors.

${ }^{4}$ Hallegatte follows this approach in his study on the optimal protection of economic capital in the light of natural disasters by referring to suboptimal decision making and its impact on the optimal protection policy (Hallegatte 2013).
} 
unproportionally high decision weight of certain outcomes), and - resulting from the certainty effect - the isolation effect (the potential of inconsistent behaviour in intransparent sequential decision problems). The findings are summarised in a table at the end of the section.

In most cases, the relevance of PT is illustrated in the framework of the stylised case described in the introduction. All examples are hypothetical, but generally feasible. In general, a more data-based approach would be desirable, but as a first demonstration of the relevance of PT in climate change decisions the approach of hypothetical, but realistic situations should also yield meaningful insights. Possible strategies for empirical analyses are outlined in the next section.

\subsection{The Relevance of the Reference Point}

In PT, the definition of a reference point is crucial for the evaluation of outcomes. The location of the reference point decides whether a final state is perceived as a gain or a loss. This is essential for the evaluation of outcomes for two reasons. Firstly, losses will be ascribed to a higher impact on the value function than nominally identical gains. Empirical evidence, mostly from experimental studies, shows that loss aversion varies around a factor of roughly two (Abdellaoui et al. 2008; Harrison and Rutstro 2008; Rieger et al. 2011; Tversky and Kahneman 1992). Secondly, the reference point is decisive for the risk attitudes of decision makers. According to the fourfold pattern of risk attitudes, both risk aversion and risk seeking may occur, depending on the loss/gain domain and the probability of uncertain events (Tversky and Kahneman 1992). ${ }^{5}$

In the context of climate change, the concept of reference dependence has considerable implications for the analysis of response measures like adaptation and mitigation. They will be presented in three steps. Firstly, the possible definitions of reference points in climate change issues are discussed. In the second step, conclusions will be drawn for the case of climate response measures with certain costs and benefits (which also hold under uncertainty). Thirdly, additional implications for measures with uncertain effects will be described.

\subsubsection{The Reference Point in the Climate Change Context}

In experimental economics, reference dependence has long been acknowledged and analysed often called framing effect (Andreoni 1995; Iturbe-Ormaetxe et al. 2011; Sonnemans et al. 1998). In environmental economics, reference dependence was brought forward in the discussion on the gap between willingness-to-pay and willingness-to-accept-compensation measures (Kahneman et al. 1990; Knetsch 2010). Yohe et al. focus on the role of the baseline scenario in evaluating benefits of coastal climate adaptation and find that adaptation benefits may depend on the baseline context - in their case, insurance availability and risk aversion (Yohe et al. 2011). In the following, it will be argued that not only the characteristics of the baseline, but also the choice of the baseline as such is not trivial.

Figure 1 depicts a typical illustration of macroeconomic costs and benefits of climate policy, in this case for adaptation. The vertical arrows symbolise the costs of adaptation (lower arrow) and its

\footnotetext{
${ }^{5}$ The fourfold pattern of risk attitudes states that for a non-mixed decision problem (either only gains or either only losses are possible) the observed dominant risk pattern is risk aversion for gains in moderate or high probabilities and for losses in low probabilities, whereas risk seeking is dominant in the domain of losses in moderate or high probabilities and gains in small probabilities, provided the outcomes are not extreme (Tversky and Kahneman 1992). The fourfold pattern can explain why the same person may purchase insurance (risk aversion in the domain of losses and low probabilities) and play lotteries (risk seeking in the domain of gains and low probabilities).
} 
benefits (upper arrow). However, the graph does not indicate where the reference point is located. Assuming an individual defines the current situation as the reference, damages by climate change and adaptation costs are conceived as losses and adaptation benefits as the reduction of losses. In this case, the reference is depicted by the horizontal axis in Figure 1. But another perspective is also possible. Perceiving climate change as an inevitable phenomenon and successful mitigation as very uncertain, a decision maker may set the reference at the already changed climate (symbolised by the "Gross Damage" line in Figure 1). For this decision maker the costs and benefits of adaptation are located in the domain of gains (adaptation benefits refer to gains, adaptation costs to the reduction of gains, gross damages of climate change are already internalised in the reference).

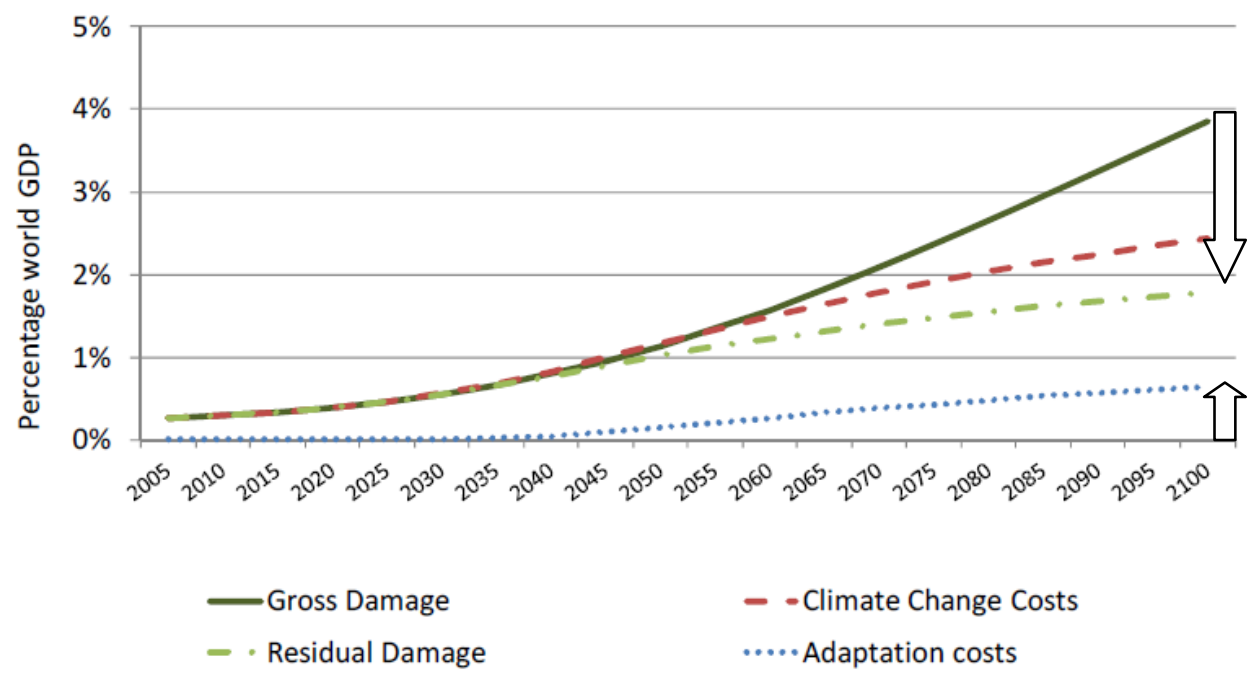

Figure 1: Illustration of adaptation benefits and costs (slightly modified extraction from Figure 8 in Agrawala et al. 2010). How to read the graph: In 2100, if no adaptation takes place, climate change will cause damages in the order of $4 \%$ of global GDP ("Gross Damage"). Adaptation reduces the damage to less than 2\% ("Residual Damage"). This reduction comes at a cost of around $0.7 \%$ ("Adaptation costs"). The total climate change costs in the case of adaptation sum up to ca. 2.5\% ("Climate Change Costs" = residual damage plus adaptation costs).

It is worth mentioning that in some (influential) publications, the climate change literature implicitly suggests the latter perspective, by labelling this path as the "reference scenario" (IPCC 2007a; UNFCCC 2007). Most probably this was not done in consideration of the reference point as used in PT, but leaves room for interpretation, whether this gross damage path can be seen as the state from which deviations are evaluated. For individuals, this perspective would mean that people anticipate climate change and mentally accommodate to its effects before they actually occur.

This notion is supported by Hulme et al. who elaborate on normality concepts in the climate change discussion (Hulme et al. 2009). One conclusion is that "normal" climates are unstable, not only in the physical dimension, but also in the cultural and psychological dimensions. Societies and individuals today may perceive a climate as "abnormal", which the same societies or individuals define as "normal" at another point in time. In other words, they acclimatise. Assuming that the reference point regarding climate depends on the climatic conditions that people perceive as "normal", this point can change over time - and even more so over generations. ${ }^{6}$

\footnotetext{
${ }^{6}$ Note that also unexpected events may shift the reference point. Think of the situation when a tipping point in the earth's climate system is reached and large-scale impacts become apparent. This may change the reference point of decision makers.
} 
On the other hand, one of the rare papers that examine climate change under a PT framework explicitly defines the current situation as the reference, but without raising this as a questionable issue, nor reasoning it comprehensively (Brekke and Johansson-Stenman 2008, page 284). This view is supported by the wide spread assumption that in many situations the status quo is considered as the reference point.

However, using the status quo as the reference point was also criticised. Particularly, Köszegi and Rabin argue that in many situations it is not plausible (Köszegi and Rabin 2007; Köszegi and Rabin 2006). Instead, they set up a model of consumption behaviour based on PT and incorporate a reference point which is defined by the consumer's "rational expectations held in the recent past about outcomes" (Köszegi and Rabin 2007, page 1133). Other authors argue for personal goals as potential reference points (Camerer et al. 1997; Farber 2008; Heath et al. 1999; Masters 2004). Another perspective is that a "safe option" is used as the reference, e.g. in the case of insurance full coverage can be assumed as the reference (Bleichrodt et al. 2001; Hershey and Schoemaker 1985; Schmidt 2012). For firms, it was argued that the average performance in the respective industry can be set as the reference (Fiegenbaum 1990), whereas for work unions the average preceding wage agreements may play this role (Mas 2006). As a consequence, if expectations (or targets) are important for the definition of the reference point in climate change decisions, and trustworthy climate projections (or target levels) are disseminated amongst decision makers, their reference point may be influenced by expected (or targeted) future climate change. ${ }^{7}$

This discussion should have made clear that the definition of the "correct" reference point is not trivial. Table 1 summarises the various possibilities how to define the reference point regarding climate change.

Table 1: Possible definitions of the reference point and their applications to global temperature change

\begin{tabular}{|l|l|l|}
\hline $\begin{array}{l}\text { Definition of the } \\
\text { reference point }\end{array}$ & Exemplary sources & $\begin{array}{l}\text { Tentative definition of reference point in } \\
\text { global temperature change }\end{array}$ \\
\hline $\begin{array}{l}\text { Status quo } \\
\text { (historical) }\end{array}$ & $\begin{array}{l}\text { (Brekke and Johansson-Stenman } \\
\text { 2008; Hulme et al. 2009) }\end{array}$ & $\begin{array}{l}\text { Average temperature of preindustrial } \\
\text { time }\end{array}$ \\
\hline $\begin{array}{l}\text { Status quo } \\
\text { (current normal) }\end{array}$ & (Hulme et al. 2009) & $\begin{array}{l}\text { Average temperature of the recent, } \\
\text { personally experienced past }\end{array}$ \\
\hline Safe outcome & $\begin{array}{l}\text { (Bleichrodt et al. 2001; Hershey } \\
\text { and Schoemaker 1985; Schmidt } \\
\text { 2012) }\end{array}$ & $\begin{array}{l}\text { Temperature which is already seen as } \\
\text { certain given the past greenhouse gas } \\
\text { emissions }\end{array}$ \\
\hline Target & $\begin{array}{l}\text { (Camerer et al. 1997; Farber 2008; } \\
\text { Heath et al. 1999; Masters 2004) }\end{array}$ & $\begin{array}{l}\text { Intended temperature ("two-degree- } \\
\text { target") }\end{array}$ \\
\hline $\begin{array}{l}\text { Rational } \\
\text { expectation }\end{array}$ & $\begin{array}{l}\text { (Köszegi and Rabin 2007; Köszegi } \\
\text { and Rabin 2006) }\end{array}$ & $\begin{array}{l}\text { Expected temperature in a given decision } \\
\text { horizon and emission scenario }\end{array}$ \\
\hline
\end{tabular}

This paper does not argue for one specific viewpoint, but shall draw the attention to the fact that which climatic situation is perceived as the reference is an unresolved question. The reason why this is important for mitigation and adaptation will be elaborated in the following subsection.

\footnotetext{
${ }^{7}$ In a recent survey amongst more than 6000 German households, the participants were asked for an estimation regarding the change in the average global surface temperature from the beginning of industrialisation to $2100.81,3 \%$ stated to expect a positive change; the median of responses was a temperature rise of 3 degree Celsius (Osberghaus et al. 2013).
} 


\subsubsection{Implications for Certain Climate Response Measures (Loss Aversion)}

How does reference dependence play into the evaluation of climate response measures, like adaptation and mitigation? First, assume climate response measures with certain costs and benefits, meaning that climate effects and response measure effects are assumed to be known ex ante.

Due to loss aversion, the location of the reference point has an effect on the cost-benefit evaluation of a response measure. More concretely, projected net benefits have a higher value to the decision maker if the outcomes are perceived in the domain of losses instead of gains. However, if alternative climate response measures are compared to each other, this should not have an effect on their relative attractiveness since the costs and benefits of all feasible options should be located in the same domain.

This changes if climate response measures have to compete with other activities. Assume a household in the stylised settlement and its decision whether to buy an air conditioner or not. Perceiving the current climate as "normality" would mean that an unpleasantly hot home is perceived as a loss, which is reduced by the air conditioner. On the contrary, if the household already expects a hotter climate and has mentally acclimatised to it, the air-conditioned home would be a gain. Due to loss aversion, this would imply a smaller monetary value of the air conditioner and thus a smaller incentive to give up alternative consumption. Figure 2 depicts this relationship graphically using a PT-type value function with loss aversion.
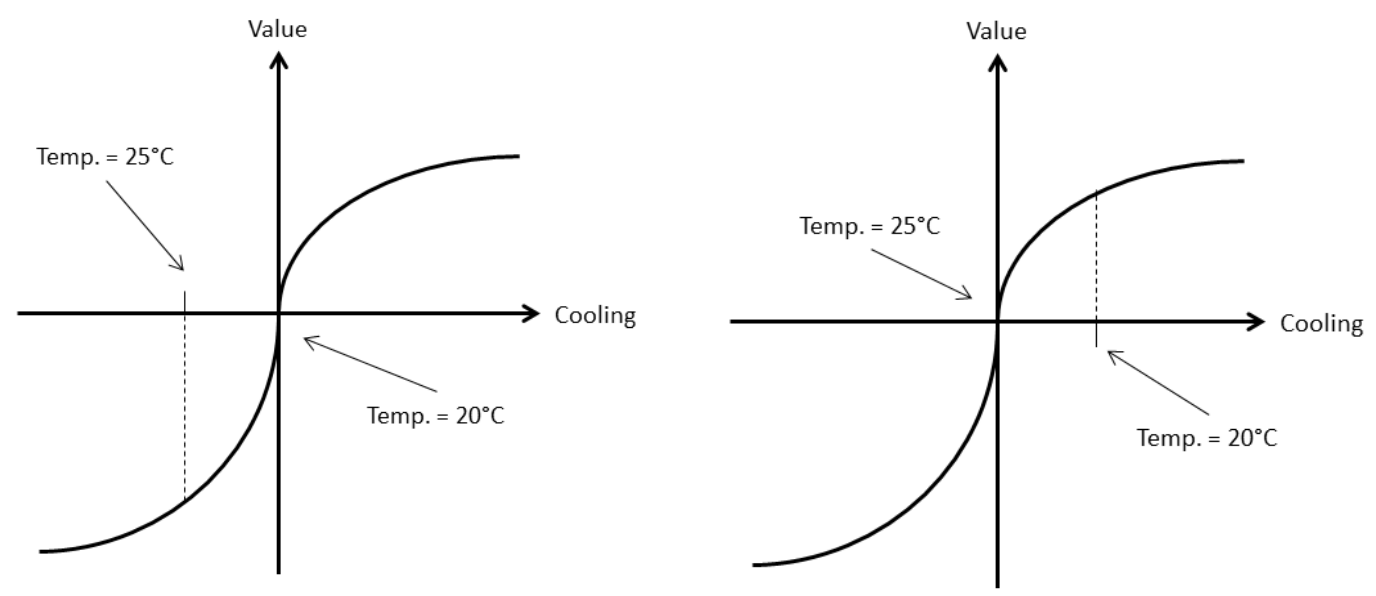

Figure 2: Illustration of a shifted reference point in the case of cooling a home. The value functions depict the value of cooling (for simplicity, it is neglected that the value of cooling decreases above a certain threshold). In the left diagram, the reference point is $20^{\circ} \mathrm{C}$, and a temperature of $25^{\circ} \mathrm{C}$ is perceived as a loss with a relatively high impact on the value. In the right panel, the reference point has shifted to $25^{\circ} \mathrm{C}$. Cooling the home to $20^{\circ} \mathrm{C}$ implies a gain with a relatively low impact on the value.

Formulated differently, an individual who sets the current temperature as his reference point and is indifferent between purchasing an air-conditioner or not, would prefer not purchasing the airconditioner if his reference point shifted to the future (higher) temperature. Hence, the relative value of climate adaptation and mitigation measures in relation to climate change-unrelated consumption is dependent on the decision maker's reference point with regard to climate change. Whether this is also relevant for collective decisions such as a nation's engagement in emission abatement is an open question as argued in the previous section. A respective empirical research design for testing this notion will be described in section 4.2. 
Moreover, note the possibility that the reference may be defined differently for the evaluations of mitigation vs. adaptation measures. Adaptation projects are often based on the implicit expectation of a changing climate - hence, a shifted reference point. It is possible that in case of a mitigation project the same decision maker may depart from the status quo situation. If this was the case, the question for the right policy mix in response to climate change (mitigation vs. adaptation) would also be reference dependent. Although speculative at this stage, a thorough analysis of such reference disparities could yield meaningful insights for the analysis of the climate policy mix.

Furthermore, reference dependence may play a role in the comparison of two different adaptation measures if the first one avoids damage and the other one yields potential benefits of climate change. As an example think of a farmer in the stylised case who - due to budget constraints - has to decide between ( $a$ ) an investment in irrigation equipment to avoid yield losses for one crop; and ( $b$ ) the purchase of fertiliser for another crop to use a prolonged vegetation period to full capacity. Assume that EUT suggests indifference between both investments. It is shown in the Appendix that the reference point with regard to expected yields is relevant for such a decision. If the current yields are perceived as the reference, loss aversion implies a relatively higher attractiveness of $(a)$ over $(b){ }^{8}$ But if the farmer has already shifted his reference point to the expected (non-adapted) yields under climate change, he would still be indifferent between both alternatives. Hence, the reference point with regard to climate impacts influences the value of adaptation measures which cope with losses compared to adaptation measures which help realising benefits of climate change.

The abovementioned effects of the reference point are relevant for adaptation and mitigation measures if their outcomes were certain, but they also hold under uncertainty. In the next step, additional effects will be presented which play a role in the analysis of climate responses under reference dependence.

\subsubsection{Implications for Uncertain Climate Response Measures}

Insurance of natural hazards is an exemplary climate response measure with uncertain outcome, as one cannot be sure whether the insured case will occur or not. Although insurance is broadly seen as an efficient adaptation to unpredictable damage events, the demand for insurance coverage is relatively low, especially for low probability / high impact events (Aakre et al. 2010; Schwarze et al. 2011). Even in the case of subsidised premiums, the demand remains remarkably low. In contrary, the demand for insurance of modest risks with a higher occurrence probability is higher, even if premiums are actuarially unfair (Kunreuther et al. 2013b). The underinsurance of improbable events has been studied by numerous authors, and several explanations have been proposed. One main argument is that small probability events are overall ignored or potential damages are broadly underestimated by decision makers (Kunreuther 1984; Kunreuther et al. 1978). Other explanations argue that the expectation of emergency relief is responsible for a low private demand (Raschky and Weck-Hannemann 2007).

As proposed by Schmidt, reference dependence can contribute to the underinsurance of low probability events. By analysing insurance demand in a theoretical model with fair premiums and applying the model with a value function as proposed by Tversky and Kahneman, the author concludes that very improbable events (with a probability lower than 0.0012 , which is, however, very

\footnotetext{
${ }^{8}$ As shown in the Appendix, this result depends on the concrete parameterisation of the value function. For the given results, the widely used parameterisation of Tversky and Kahneman is assumed. Additionally, the adaptation costs have to be somewhat lower than the benefits.
} 
sensitive to the parameterisation of the value function) will not be insured, while events with a higher probability are fully insured (Schmidt 2012). Interestingly, this result crucially depends on the reference point, which is defined here as the safe option with regard to insurance coverage (i.e. final wealth after buying full insurance). Hence, the reference point with regard to insurance coverage may be relevant for the question whether a decision maker purchases insurance for low probability events, such as natural hazards. Note that this analysis neglects probability weighting and the certainty effect in order to isolate the effect of reference dependence.

In addition to loss aversion, the fourfold pattern of risk attitudes (see footnote 5) becomes important for the ex ante evaluation of climate response measures with uncertain outcomes. As an example, think of an adaptation measure which has a moderate probability of being effective, but low costs e.g. air brick covers as a physical flood protection device for private homes. Assume a substitute proactive measure is the moving of valuable assets to higher floors, which is costlier but less risky. If the home owner defines the status quo as the reference point, damages due to more frequent floods would be perceived in the domain of losses and the benefits of protection as avoided losses.

According to the fourfold pattern, and if the probability of a flood event is deemed as low (moderate or high), risk aversion (risk seeking) would be the dominant risk attitude in this case. Then, PT would imply a tendency towards the less risky (riskier) alternative - if EUT suggests indifference. In the other case - setting the reference to the future situation - no general conclusion can be drawn for the dominant risk attitude since positive and negative outcomes are possible and the fourfold pattern is not applicable. Hence, the reference point with regard to the climatic situation may be relevant for the question whether a decision maker is risk averse or risk seeking with regard to uncertain climate response measures and thereby affect the values ascribed to these measures.

Note that the fourfold pattern of risk attitudes does not hold for very large outcomes. As a consequence, the described effects would not be plausible if significant assets were at risk, such as whole buildings. This implies that decisions on the national level or large-scale mitigation and adaptation projects are probably not subject to the fourfold pattern of risk attitudes. Moreover, the concept of the fourfold pattern of risk attitudes does not hold when positive and negative outcomes are combined in one decision problem.

\subsection{The Certainty Effect}

In PT, the certainty effect describes the observation that individuals ascribe a disproportionally high value to certain events, higher than EUT with risk aversion can plausibly incorporate. The Allaisparadox is probably the most prominent example (Allais 1953).

This proposition offers a broad array of possible illustrations in the context of climate change. For example, it may explain why there is demand for insurance which exceeds the expected value of the contract (Botzen and van den Bergh 2009; Sydnor et al. 2010), provided that insurance coverage is regarded as certain (Stewart and Stewart 2001). ${ }^{9}$ Formulated conversely, the willingness to pay for

\footnotetext{
${ }^{9}$ It may be confusing that, on the one hand, PT can explain high insurance demand (by the certainty effect, see this subsection) and, on the other hand, low insurance demand (by reference dependence, see the preceding subsection). Indeed, two opposing effects are present and it is an open empirical question which effect dominates (Barberis 2013a, page 613). The cited literature on PT and insurance deals with that by focusing on the respective effect of interest, while the other is explicitly or implicitly neglected (Schmidt 2012, page 3; Wakker et al. 1997).
} 
an insurance contract decreases unproportionally if the probability of loss coverage is not certain. ${ }^{10}$ Hence, the willingness to pay for insurance contracts which are profitable for the insurance industry may be partly grounded in the expectation that the probability of bearing a loss is not only reduced, but totally eliminated by the insurance contract.

A similar case can be found in a study amongst Dutch homeowners, in which insurance coverage after a flood event is assumed to be uncertain (Botzen et al. 2013). The authors frame a technical elevation of homes as a total elimination of flood risk and find that the "safety premium" that individuals place on the elimination of the risk, compared to the willingness to pay for flood insurance, is indeed positive and substantial. The authors explain this by referring to the certainty effect and the possible expectation of individuals that insurance companies may be unwilling or unable to pay claims after large natural disasters (Botzen et al. 2013, page 238; Stewart and Stewart 2001).

A further example can be located on a more general level. The coastal adaptation literature distinguishes general broad strategies, namely "Protect", "Accommodate", and "Retreat", where the "Protect" strategy can be subdivided into soft and hard protection (IPCC 2007b; Klein et al. 2001; for a discussion on inland flood protection: Kundzewicz 2002; Meyer et al. 2012). Assume the exposed community in the stylised case had to decide between these general strategies. The concrete technical options that are named as examples in Klein et al. may be perceived as more or less certain regarding their effectiveness by decision makers. For example, accommodate options (such as emergency planning) and some soft protection options (such as dune restoration and creation) may leave a sense of uncertainty with the decision makers, who are often experienced in terms of conventional, hard protection options. ${ }^{11}$ As a result, many decision makers could see hard protection options as certainty promising, although this expectation may not always be correct. If decision makers expect a total elimination of risks by pursuing some coastal adaptation option, while they perceive any residual risk in another option, the certainty effect implies that the former appears relatively attractive.

Kahneman and Tversky present a specific phenomenon, which is based on the certainty effect, namely "probabilistic insurance". They construct the following decision problem: Assume a decision maker is indifferent towards taking a risk of losing $x$ with a probability $0<p<1$ and an insurance contract covering that risk for the premium $y$. Another insurance contract would cover the loss $x-$ if it occurs - only with a probability $0<r<1$, and the premium would be $r y$. In case the damage occurs and the insurance covers the loss (which occurs with a probability of $r^{*} p$ ), the premium is raised to $y$. In case the damage occurs and the insurance does not pay (which has a probability of $(1-r)^{*} p$ ), the premium is lowered to zero. Empirical studies confirm what intuition suggests: A clear unattractiveness of such insurance contracts, given that the conventional insurance was considered as just fair. However, under EUT and risk aversion it can be proven that the probabilistic insurance is strictly preferred to the conventional insurance (Kahneman and Tversky 1979, page 270).

\footnotetext{
${ }^{10}$ Wakker et al. show that consumers demand a premium reduction of more than $20 \%$ if the probability of loss coverage decreases from $100 \%$ to $99 \%$ (Wakker et al. 1997). This is one important argument of Stewart and Stewart for avoiding such an expectation amongst insurance customers (Stewart and Stewart 2001).

${ }^{11}$ Anecdotic evidence for this can be found in policy papers and reports (Doswald and Osti 2011, page 23; Regierungskommission Klimaschutz 2012, pages 51-55). Evidence that soft protection measures imply higher uncertainty than hard protection is apparent in cost-benefit-analyses (Brouwer and van Ek 2004; Meyer et al. 2012). This uncertainty also hampers public acceptance (Weisner and Schernewski 2013).
} 
Why is this seemingly constructed decision problem relevant? Kahneman and Tversky argue that many decision problems in real life are similar to probabilistic insurance as they come with certain costs but uncertain effects. They mention the examples of replacing old tires, installing a burglar alarm and the decision to stop smoking. ${ }^{12}$ The connection to climate response measures is obvious: Often, their costs are known ex ante, but their effectiveness is not. The concept of probabilistic insurance becomes relevant if alternative options are feasible, some of them similar to probabilistic insurance and others not. One example is a household's decision how to respond to flood risks. Either physical flood barriers (e.g. air brick covers) may be installed or the household insures against the monetary flood loss. The former strategy incurs some uncertainty regarding its effectiveness, but comes at lower costs than the latter (assuming that one-time installation costs can be compared to insurance premiums by annualisation). The certainty effect of PT suggests that - provided the insurance coverage in case of a flood is perceived as certain - the insurance solution would probably be preferred over technical protection. Indeed, most technical adaptation measures imply certain costs and uncertain benefits and may therefore be less attractive than alternative financial solutions like insurance contracts, if their effectiveness is seen as certain.

This insight may also be used within the domain of insurance markets: The certainty effect would have implications on the attractiveness of an insurance covering multiple perils (but none surely) relative to an insurance covering a specific danger, but this one for sure (Kahneman and Tversky 1979, page 271; Tversky and Kahneman 1981, page 456). Turning to the stylised case, farmers may meet a decision between two types of crop insurance, namely between $(a)$ an index-based ${ }^{13}$ multiperil insurance and $(b)$ an indemnity-based single-peril insurance. In such a situation, the certainty effect implies preferences which are dependent on the certainty definition of the specific farmer. Let him assess certainty by the probability of full reimbursement after a specific event, e.g. hail. In this case, he would by tendency prefer insurance type (b) since only then he can be sure of being fully reimbursed after a devastating hailstorm. Conversely, another farmer could perceive certainty in the sense that any weather-related hazard shall be taken into account (e.g. hail, storm, drought, floods). For such a farmer insurance type (a) would offer the desired certainty.

To conclude, the certainty effect implies that risk management measures that are perceived as riskeliminating are preferred over measures that are perceived as risk-reducing, even when their expected utilities under EUT with risk aversion would suggest indifference. This effect is relevant for a number of climate change decisions, particularly in the field of adaptation.

\subsection{The Isolation Effect}

The isolation effect as presented in PT highlights inconsistent behaviour in sequential decision problems. It can be seen as a special case of the certainty effect. Assume a set of decision problems as depicted in Figure 3.

\footnotetext{
${ }^{12}$ By this statement, they implicitly neglect the effect of an ex post changed insurance premium. The rest of this section builds on the statement of Kahneman and Tversky that probabilistic insurance is indeed sufficiently similar to the mentioned examples.

${ }^{13}$ Index-based insurances are frequently discussed as an appropriate strategy to adapt to increasing climatic variability (Herweijer et al. 2009; Hochrainer et al. 2009; Linnerooth-Bayer and Mechler 2006)
} 

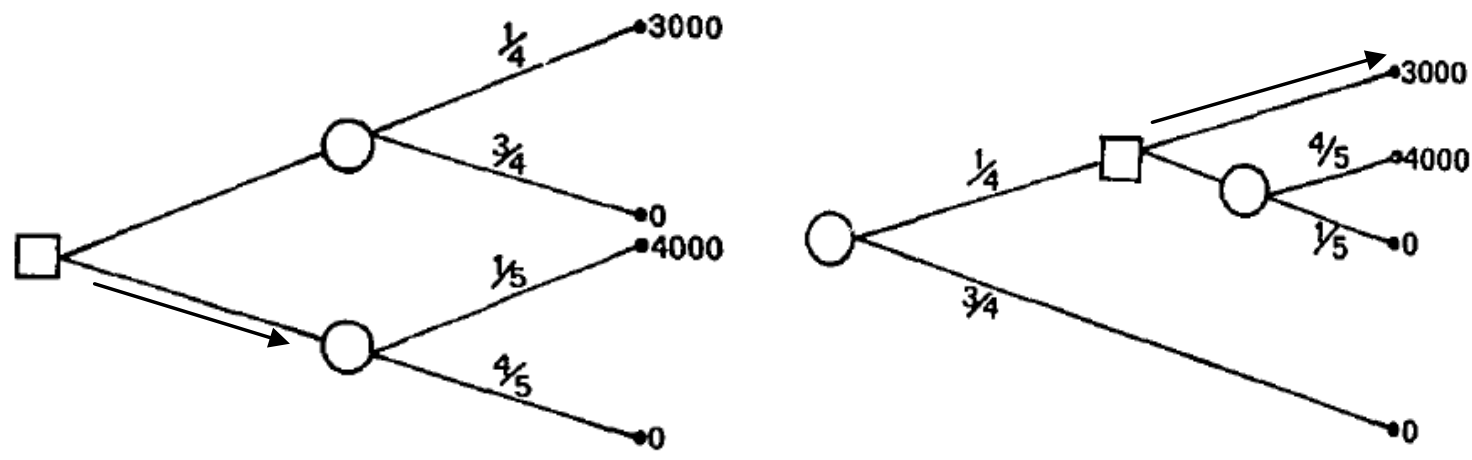

Figure 3: Decision trees for two hypothetical sequential decision problems. Squares denote decision nodes and circles denote chance nodes. In the right panel, the decision has to be made before the first game is played. Arrows mark the preferred decisions according to the empirical findings of Kahneman and Tversky (Modified Figure 1 and 2 from Kahneman and Tversky 1979, page 272).

Both problems are effectively identical in terms of expected outcome, since they can be merged to a decision between a $25 \%$ chance winning 3000 and a $20 \%$ chance of winning 4000 . The rest of the cases yield zero in both choices. However, experiments show that most individuals choose the options as marked by the arrows in Figure 3, although these choices are inconsistent with each other (Kahneman and Tversky 1979, page 271). This is because people perceive the problems differently, depending on the sequence of choices and stochastic events. In the right panel of Figure 3 , the option of winning 3000 is perceived as a certain event, although it has exactly the same probability as in the problem on the left side.

What does this phenomenon imply for the analysis of climate change responses? Climate change impact and respective responses are subject to uncertainties on various levels and at different time steps and as such they can be described as sequential decision problems. Assume that the community in the stylised case has opted for the coastal adaptation strategy "Protect" in response to the risk that the sea level will surpass a critical threshold in the future. If this threshold is going to be surpassed, adaptation is necessary today in order to ensure the future protection. The alternative options for protection - which are equally costly - may be (a) hard structures such as a dyke, which is perceived by the decision makers as certainly effective, and (b) the enhancement of natural barriers such as wetlands which has a perceived uncertainty in effectiveness (see preceding subsection), but which brings co-benefits, e.g. in terms of ecosystem services or recreational value. This is an example which can be easily be captured in the same way as the one presented in Figure 3. Just label the outcome 3000 as the gross benefit of the hard protection and the outcome 4000 of the soft protection, respectively. Assume further that the probability of surpassing the threshold is approximately $25 \%$ and the expected probability of ineffectiveness of the soft measure $20 \%{ }^{14}$

Hence, for the desirability of the specific options it can be relevant how the decision problem is perceived: Whether the decision is met under the presumption that adverse climate impacts are actually occurring (as in the right panel of Figure 3) or whether this impact uncertainty is integrated into the evaluation of the different policy options (as in the left panel of Figure 3). Since climate

\footnotetext{
${ }^{14}$ This assumes that the future situation serves as the reference and the adaptation costs are already incorporated in the reference (which is plausible according to Kahneman and Tversky 1979, page 271). These and other restrictions had to be made in order to fit the problem into the numbers of Figure 3 . The crucial issue, however, namely that certainty effects can occur in one formulation and can be absent in another formulation of the same sequential decision problem, can also be present when these assumptions are relaxed.
} 
impacts are generally uncertain, this aspect seems to be relevant in the ex ante evaluation of virtually all proactive climate response measures with uncertain costs and benefits, including mitigation.

\subsection{Summary of Effects}

Table 2 summarises the presented decision problems and respective assumptions under which PT proposes different results than a conventional EUT approach. 
Table 2: Summary of decision problems in the climate change context where effects described by prospect theory are relevant, in the order of appearance in the paper.

\begin{tabular}{|c|c|c|c|c|c|}
\hline $\begin{array}{l}\text { Decision problem in the } \\
\text { climate change context }\end{array}$ & $\begin{array}{l}\text { Assumed } \\
\text { tendency } \\
\text { implied by EUT }\end{array}$ & $\begin{array}{l}\text { Possible perceptions regarding } \\
\text { reference point or certainty }\end{array}$ & $\begin{array}{l}\text { Resulting tendency } \\
\text { implied by PT }\end{array}$ & $\begin{array}{l}\text { Relevant } \\
\text { effects }\end{array}$ & Example in the stylised case \\
\hline \multirow[t]{2}{*}{$\begin{array}{l}\text { Climate response } \\
\text { measure vs. alternative } \\
\text { measure outside the } \\
\text { climate context }\end{array}$} & \multirow[t]{2}{*}{ Indifference } & $\begin{array}{l}\text { Current climate is perceived as the } \\
\text { reference. Effects of climate } \\
\text { response located in the domain of } \\
\text { losses. }\end{array}$ & $\begin{array}{l}\text { Higher value of climate } \\
\text { response, hence } \\
\text { preference for climate } \\
\text { response measure. }\end{array}$ & \multirow[t]{2}{*}{$\begin{array}{l}\text { Reference } \\
\text { dependence } \\
\text { and loss } \\
\text { aversion }\end{array}$} & \multirow[t]{2}{*}{$\begin{array}{l}\text { Household's decision to buy } \\
\text { an air conditioner. }\end{array}$} \\
\hline & & $\begin{array}{l}\text { Future climate is perceived as the } \\
\text { reference. Effects of climate } \\
\text { response located in the domain of } \\
\text { gains. }\end{array}$ & $\begin{array}{l}\text { Lower value of climate } \\
\text { response, hence } \\
\text { preference for alternative } \\
\text { measure outside the } \\
\text { climate context. }\end{array}$ & & \\
\hline Mitigation vs. adaptation & Indifference & $\begin{array}{l}\text { The climate reference point for } \\
\text { mitigation is unequal to reference } \\
\text { point for adaptation. }\end{array}$ & $\begin{array}{l}\text { The strategy where the } \\
\text { current climate is } \\
\text { perceived as the reference } \\
\text { is preferred. }\end{array}$ & $\begin{array}{l}\text { Reference } \\
\text { dependence } \\
\text { and loss } \\
\text { aversion } \\
\end{array}$ & None \\
\hline \multirow[t]{2}{*}{$\begin{array}{l}\text { Adaptation to losses vs. } \\
\text { adaptation to benefits }\end{array}$} & \multirow[t]{2}{*}{ Indifference } & $\begin{array}{l}\text { Status quo is perceived as the } \\
\text { reference point and } \\
\text { parameterisation of Tversky and } \\
\text { Kahneman is assumed. }\end{array}$ & $\begin{array}{l}\text { Preference for adaptation } \\
\text { to losses. }\end{array}$ & $\begin{array}{l}\text { Reference } \\
\text { dependence } \\
\text { and loss } \\
\text { aversion } \\
\end{array}$ & \multirow[t]{2}{*}{$\begin{array}{l}\text { Farmer's decision to invest in } \\
\text { irrigation for disadvantaged } \\
\text { crop A vs. fertiliser for } \\
\text { benefited crop B. }\end{array}$} \\
\hline & & $\begin{array}{l}\text { Future situation is perceived as the } \\
\text { reference point. }\end{array}$ & $\begin{array}{l}\text { Indifference (as in } \\
\text { expected utility) }\end{array}$ & No effect & \\
\hline \multirow[t]{3}{*}{$\begin{array}{l}\text { Risky climate response } \\
\text { measure vs. less risky } \\
\text { response measure }\end{array}$} & \multirow[t]{3}{*}{$\begin{array}{l}\text { Indifference } \\
\text { after accounting } \\
\text { for risk aversion }\end{array}$} & $\begin{array}{l}\text { Status quo is perceived as the } \\
\text { reference point and climate impact } \\
\text { is deemed as very improbable. }\end{array}$ & $\begin{array}{l}\text { Risk aversion: Less risky } \\
\text { response measure is } \\
\text { preferred. }\end{array}$ & \multirow{2}{*}{$\begin{array}{l}\text { Reference } \\
\text { dependence } \\
\text { and } \\
\text { fourfold } \\
\text { pattern of } \\
\text { risk } \\
\text { attitudes }\end{array}$} & \multirow{3}{*}{$\begin{array}{l}\text { Home owner's decision to } \\
\text { install air brick covers vs. } \\
\text { moving valuable assets to } \\
\text { higher floors. }\end{array}$} \\
\hline & & $\begin{array}{l}\text { Status quo is perceived as the } \\
\text { reference point and climate impact } \\
\text { is deemed as moderately probable. }\end{array}$ & $\begin{array}{l}\text { Risk seeking: Riskier } \\
\text { response measure is } \\
\text { preferred. }\end{array}$ & & \\
\hline & & $\begin{array}{l}\text { Future situation is perceived as the } \\
\text { reference point. }\end{array}$ & $\begin{array}{l}\text { Fourfold pattern of risk } \\
\text { attitudes not applicable. }\end{array}$ & No effect & \\
\hline
\end{tabular}




\begin{tabular}{|c|c|c|c|c|c|}
\hline $\begin{array}{l}\text { Decision problem in the } \\
\text { climate change context }\end{array}$ & $\begin{array}{l}\text { Assumed } \\
\text { tendency } \\
\text { implied by EUT }\end{array}$ & $\begin{array}{l}\text { Possible perceptions regarding } \\
\text { reference point or certainty }\end{array}$ & $\begin{array}{l}\text { Resulting tendency } \\
\text { implied by PT }\end{array}$ & $\begin{array}{l}\text { Relevant } \\
\text { effects }\end{array}$ & Example in the stylised case \\
\hline \multirow{2}{*}{$\begin{array}{l}\text { Decision to purchase } \\
\text { insurance against } \\
\text { extreme weather } \\
\text { events }^{15}\end{array}$} & \multirow{2}{*}{$\begin{array}{l}\text { Indifference } \\
\text { after accounting } \\
\text { for risk aversion }\end{array}$} & $\begin{array}{l}\text { Loss coverage is perceived as } \\
\text { certain. }\end{array}$ & Preference for insurance & $\begin{array}{l}\text { Certainty } \\
\text { effect }\end{array}$ & \multirow[t]{2}{*}{$\begin{array}{l}\text { Household's decision to } \\
\text { purchase flood insurance. }\end{array}$} \\
\hline & & $\begin{array}{l}\text { Full insurance is perceived as the } \\
\text { reference point. }\end{array}$ & $\begin{array}{l}\text { Preference for non- } \\
\text { insuring events with a } \\
\text { probability under a } \\
\text { threshold probability. }\end{array}$ & $\begin{array}{l}\text { Reference } \\
\text { dependence } \\
\text { and loss } \\
\text { aversion }\end{array}$ & \\
\hline $\begin{array}{l}\text { Coastal adaptation } \\
\text { strategies: Retreat, } \\
\text { Protect or Accommodate } \\
\text { to sea level rise }\end{array}$ & $\begin{array}{l}\text { Indifference } \\
\text { after accounting } \\
\text { for risk aversion }\end{array}$ & $\begin{array}{l}\text { It is perceived that the risk of } \\
\text { losses is totally eliminated by one } \\
\text { of the strategies. }\end{array}$ & $\begin{array}{l}\text { Preference for the strategy } \\
\text { with a certainty bonus. }\end{array}$ & $\begin{array}{l}\text { Certainty } \\
\text { effect }\end{array}$ & $\begin{array}{l}\text { Community's decision for } \\
\text { coastal adaptation strategy. }\end{array}$ \\
\hline $\begin{array}{l}\text { Insurance vs. technical } \\
\text { protection }\end{array}$ & $\begin{array}{l}\text { Indifference } \\
\text { after accounting } \\
\text { for risk aversion }\end{array}$ & $\begin{array}{l}\text { Insurance coverage is deemed as } \\
\text { certain. }\end{array}$ & $\begin{array}{l}\text { Insurance has a certainty } \\
\text { bonus and is preferred. }\end{array}$ & $\begin{array}{l}\text { Certainty } \\
\text { effect }\end{array}$ & $\begin{array}{l}\text { Household's decision } \\
\text { between flood insurance and } \\
\text { technical flood protection. }\end{array}$ \\
\hline $\begin{array}{l}\text { Decision between } \\
\text { different insurance types }\end{array}$ & $\begin{array}{l}\text { Indifference } \\
\text { after accounting } \\
\text { for risk aversion }\end{array}$ & $\begin{array}{l}\text { One type of insurance is perceived } \\
\text { as a contract with certain coverage, } \\
\text { another one is not. }\end{array}$ & $\begin{array}{l}\text { Preference for the type of } \\
\text { insurance with a certainty } \\
\text { bonus. }\end{array}$ & $\begin{array}{l}\text { Certainty } \\
\text { effect }\end{array}$ & $\begin{array}{l}\text { Farmer's decision whether to } \\
\text { purchase index-based multi- } \\
\text { peril insurance or indemnity- } \\
\text { based single-peril insurance. }\end{array}$ \\
\hline $\begin{array}{l}\text { Evaluation of proactive } \\
\text { climate response } \\
\text { measures with uncertain } \\
\text { effects }\end{array}$ & $\begin{array}{l}\text { No effect of } \\
\text { formulation of } \\
\text { decision } \\
\text { problem on the } \\
\text { preferences }\end{array}$ & $\begin{array}{l}\text { Certainty effects can occur in one } \\
\text { formulation and in another one } \\
\text { not. }\end{array}$ & $\begin{array}{l}\text { Preferences can change } \\
\text { according to formulation } \\
\text { of decision problem. }\end{array}$ & $\begin{array}{l}\text { Isolation } \\
\text { effect }\end{array}$ & $\begin{array}{l}\text { Community's decision about } \\
\text { proactive coastal protection. }\end{array}$ \\
\hline
\end{tabular}

\footnotetext{
${ }^{15}$ Regarding the opposing effects of the certainty effect and reference dependence, see footnote 9 on page 12.
} 


\section{Possible Empirical Applications}

\subsection{Challenges}

This section presents possible starting points for empirical applications of prospect theory (PT) in the field of climate change. In relation to its wide-spread acceptance in economic and psychological literature for more than thirty years, PT has rarely been applied in empirical economic studies. One important reason is that the definition of the reference point in many real world economic decisions is not trivial (Barberis 2013b, page 178; DellaVigna 2009; Levy 1996). A "natural" reference point can be expected in decisions on financial investments, where a risk-free interest rate or an initial purchase price can serve as the reference, but rarely in other fields. This reference uncertainty obviously complicates a quantitative analysis and hypothesis testing. In an overview on reference point definitions in political studies, Mercer presents five broad strategies: using the status quo, aspirations, heuristics, analogies and emotions (Mercer 2005). For each of these reference point concepts, historical examples from the political sphere are mentioned - a sound empirical strategy for testing the stated hypotheses is, however, missing. The strategy to use rationally expected future outcomes as the reference (Köszegi and Rabin 2006) offers a catchy solution to this challenge, but also this proposal "remains a hypothesis in need of more testing and [...] is unlikely to be completely correct" (Barberis 2013b, page 192). Hence, the reference uncertainty remains one major obstacle in the empirical application of PT in economic questions and therefore also in the applications outlined here. Yet, there are few psychological field studies which elicit the reference points of individuals in different contexts: Creyer and Ross Jr define the reference point regarding the ethical behaviour of firms as the respective consumers' expectations and elicit these by a series of questionnaire items (Creyer and Ross Jr 1997). Another way - if individual goals are assumed as reference points - is to conduct personal interviews on satisfaction with current states and to derive the reference points accordingly (Masters 2004). These examples show that first a specific reference point concept has to be assumed (e.g. using expectations or goals) before individual reference points can be elicited. Turning to the climate context: If - according to Köszegi and Rabin - individual expectations of future climate impacts are accepted as a proxy for the reference point, surveys could elicit these expectations.

Even if the reference point can be derived, it is not probable that PT explains observed behaviour exclusively. As empirical studies suggest, some decision makers / decisions may be best described by PT, while for other observations in the same sample expected utility may work better (Bruhin et al. 2010; Harless and Camerer 1994; Harrison and Rutström 2009; Hey and Orme 1994). Hence, in empirical tests of PT this individual heterogeneity should be taken into account. One solution is the use of finite mixture models, which ascribe the probability that a given model describes the decision process to each observation (Bruhin et al. 2010; Harrison and Rutström 2009). When applied to climate change, this should also provide an indication of the overall relevance of PT in this specific context.

Other climate-specific challenges to the application of PT are mentioned in section 2. They include careful and case-wise considerations whether PT is an appropriate model for collective decisions and the awareness that PT is by construction a purely descriptive theory. The latter is highly relevant for the attempt to conclude policy recommendations. 


\subsection{Applications with Regard to Reference Dependence}

Any empirical study attempting to analyse the reference dependence of climate response measures will be bound to some definition of the reference point. Thus, the applications presented in this subsection hinge on the assumption that climate reference points for individuals can be defined and indeed vary.

One possible way to study the effects of reference dependence are stated-preferences studies on the willingness-to-pay for hypothetical mitigation or adaptation measures. Given individual reference points, the monetary value people place on these measures should depend inter alia on these references.

Another possibility is to review national climate policies, such as adaptation strategies or renewable energy subsidies, or the position in international climate negotiations. If majority opinions in different countries systematically differed in their definition of the climate change reference, different climate policies of the national governments could partly be explained by this fact. Let country $A$ be a country in which the majority sees the changed future climate as the reference. Positive effects of climate policy would be perceived as gains. In another country $B$, where the public opinion tends to see the current climate as the reference, effects of climate policy are evaluated within the loss domain. ${ }^{16}$ Loss aversion implies that climate policy effects would be evaluated higher in country $B$ than in $A$. Hence, country $B$ rather than country $A$ would tend to forego other costly policies such as development projects or social security programs for the sake of climate policy. This relationship of public perception of climate change and national policies will be testable if the predominant reference points in different countries are measured and indeed vary.

Similar to governments, stakeholder or lobby groups could be influenced by their interpretation of the climate reference. By text analytics, the explicit and implicit information about the reference point can possibly be identified in written and oral communications and publications. This information, in turn, could be used to explain expressed preferences of the publishing group and/or exhibit a communication strategy which uses the effects of the specific reference dependence. First anecdotic evidence suggests that, when speaking about climate impacts, environmental NGO's tend to stress expected adverse impacts (effects are located implicitly in the loss domain), whereas conservative think tanks put relative emphasis on the fact that global warming is already inevitable (gain domain) (350.org 2013; American Enterprise Institute 2012; Cato Institute 2012, page 12; Greenpeace International 2013). That needs to be analysed in much more depth than intended in this paper. Even if the emphasis on different scenarios was intended for other reasons or not intended at all, it could have an effect on the evaluation of climate policies as well.

\subsection{Applications with Regard to the Certainty Effect}

As in the case of the reference dependence, also the certainty effect can be analysed in the framework of stated-preferences studies. Wakker et al. employ a stated-preferences experiment in order to show the certainty effect in hypothetical home insurance decisions (Wakker et al. 1997). Building on this work, one could approach the open empirical question how the opposing effects of PT regarding the demand for insurance of low probability events interact (recall that the certainty

\footnotetext{
${ }^{16}$ Instead finding the predominant reference point within the population of a country, an obvious first step would be an analysis how policy makers or climate negotiators of the given country define the climate reference. In autocratic regimes, this would be even more appropriate than the public perception.
} 
effect speaks for an attractiveness of insurance contracts while reference dependence may be a reason for the puzzling low demand for insurance of low probability events; see footnote 9). Hence, it could be fruitful to design a stated preferences experiment which elicits the willingness to pay for these insurance contracts under different controlled framings in order to capture possible effects of reference dependence (e.g. already fully insured vs. not insured at all) and certainty perception.

In a similar vein, preferences for certain financial precaution (insurance) and uncertain physical protection could be tested, while accounting for individual heterogeneity in terms of predominant decision models by finite mixture models. Also in the decision problem on natural hazard insurance an empirical test on certainty preferences is feasible. Offering different insurance contracts (one covering a single peril for sure and another covering multiple perils but none surely) could reveal preferences for different kinds of certainty. The insights could shed more light on the monetary valuation of certainty and provide meaningful information to insurance suppliers, especially in the agricultural insurance segment.

\section{Conclusion}

This paper elaborates on the role of prospect theory in the analysis and evaluation of climate response measures (adaptation and mitigation). Prospect theory offers a number of insights which are highly relevant for the analysis of adaptation and mitigation but rarely considered in the existing literature (for a summary of effects described in this paper see Table 2). Several application opportunities are proposed which are more data-based than the illustrative examples used here, including a discussion of some specific challenges.

In summary, the following aspects have emerged: The definition of a reference point implies whether the effects of a given response measure are perceived in the domain of losses or in the domain of gains. This is crucial for the evaluation of outcomes by the decision maker. It was shown that reference dependence can contribute to explain why some actors prefer aggressive climate mitigation and adaptation, while others are more reluctant to climate-related action. By the perception of certainty, outcomes which are perceived as certain get a disproportionally high decision weight, higher than expected utility theory with plausible risk aversion can accommodate. This certainty effect may also be present in intransparent, sequential decision problems, such as the ex-ante evaluation of proactive adaptation measures.

The bottom line of these effects is the importance of the way how a decision problem is perceived by the decision maker (in particular: which domain and whether outcomes are perceived as certain). As a consequence, the topic of framing emerges. Framing potentially affects the perception of climate scenarios: Whether the state of today is seen as the reference scenario or whether the gross damage path / the inaction scenario is conceived as the reference. The former notion implies a higher value of climate response measures to the decision maker than the latter. Framing can also influence the perception whether an outcome is certain or not. Those outcomes which are perceived as certain are by tendency more attractive than others which leave some feeling of uncertainty. Effects of different climate policy framings have been found for renewable energy policies in the UK (Lockwood 2011), but the framing effects suggested by prospect theory have not yet been tested empirically.

Obviously, the effects presented in this paper can never fully explain observed adaptation and mitigation behaviour. It is possible that in some case drivers such as the expected magnitude of 
climate impacts or the danger of free-riding dominate possible effects from PT. Moreover, if decision makers face the risk of a very high or total lost, diminishing sensitivity in the value function will no longer be plausible and other effects will dominate the decision. This, however, does not preclude that reference dependence and certainty perception have a measurable and potentially decisive impact in other decision problems related on climate change. For example, the free-riding problem does not occur in many adaptation decisions.

Several research possibilities emerge from these insights. One important topic for future research is the reference dependence of individual climate action and national climate policies. Further promising research lines are mentioned in the preceding section.

After all, by ignoring the insights of prospect theory, one takes the risk of neglecting well-researched behavioural patterns in decisions under uncertainty. A consideration of these insights, in turn, will be a value added in the positive analysis of uncertainty in climate change adaptation and mitigation. The findings can help to design climate policies which are more appropriate and promising than without the consideration of the effects described by prospect theory.

\section{References}

350.org (2013) 350.org. www.350.org. Accessed 25 Apr 2013

Aakre S, Banaszak I, Mechler R, et al. (2010) Financial adaptation to disaster risk in the European Union. Mitig Adapt Strateg Glob Chang 15:721-736. doi: 10.1007/s11027-010-9232-3

Abdellaoui M, Bleichrodt $\mathrm{H}$, L'Haridon $\mathrm{O}$ (2008) A tractable method to measure utility and loss aversion under prospect theory. J Risk Uncertain 36:245-266. doi: 10.1007/s11166-008-9039-8

Adger WN, Hughes TP, Folke C, et al. (2005) Social-ecological resilience to coastal disasters. Science 309:1036-9. doi: 10.1126/science.1112122

Agrawala S, Bosello F, Carraro C, et al. (2010) Plan or React? Analysis of Adaptation Costs and Benefits Using Integrated Assessment Models. doi: 10.1787/5km975m3d5hb-en

Allais M (1953) Le comportement de l'homme rationnel devant le risque: Critique des postulats et axioms de l'ecole Americaine. Econometrica 21:503-546.

American Enterprise Institute (2012) Natural disasters: Who pays in the climate change era? http://www.aei.org/article/energy-and-the-environment/climate-change/natural-disasterswho-pays-in-the-climate-change-era/. Accessed 25 Apr 2013

Andreoni J (1995) Warm-Glow versus Cold-Prickle: The Effects of Positive and Negative Framing on Cooperation in Experiments. Q J Econ 110:1-21.

Barberis N (2013a) The Psychology of Tail Events: Progress and Challenges. Am Econ Rev 103:611616.

Barberis NC (2013b) Thirty Years of Prospect Theory in Economics: A Review and Assessment. J Econ Perspect 27:173-196. doi: 10.1257/jep.27.1.173 
Van den Bergh JCJ., Ferrer-i-Carbonell A, Munda G (2000) Alternative models of individual behaviour and implications for environmental policy. Ecol Econ 32:43-61. doi: 10.1016/S09218009(99)00088-9

Bichard E, Kazmierczak A (2012) Are homeowners willing to adapt to and mitigate the effects of climate change? Clim Change 112:633-654. doi: 10.1007/s10584-011-0257-8

Birnbaum MH (2008) New paradoxes of risky decision making. Psychol Rev 115:463-501. doi: 10.1037/0033-295X.115.2.463

Bleichrodt H, Pinto JL, Wakker PP (2001) Making Descriptive Use of Prospect Theory to Improve the Prescriptive Use of Expected Utility. Manage Sci 47:1498-1514. doi: 10.1287/mnsc.47.11.1498.10248

Botzen WJW, Aerts JCJH, Bergh JCJM (2013) Individual preferences for reducing flood risk to near zero through elevation. Mitig Adapt Strateg Glob Chang 18:229-244. doi: 10.1007/s11027-0129359-5

Botzen WJW, van den Bergh JCJM (2009) Bounded Rationality, Climate Risks, and Insurance: Is There a Market for Natural Disasters? Land Econ 85:265-278.

Brekke KA, Johansson-Stenman O (2008) The behavioural economics of climate change. Oxford Rev Econ Policy 24:280-297. doi: 10.1093/oxrep/grn012

Brouwer R, van Ek R (2004) Integrated ecological, economic and social impact assessment of alternative flood control policies in the Netherlands. Ecol Econ 50:1-21. doi:

10.1016/j.ecolecon.2004.01.020

Bruhin A, Fehr-Duda H, Epper T (2010) Risk and Rationality: Uncovering Heterogeneity in Probability Distortion. Econometrica 78:1375-1412. doi: 10.3982/ECTA7139

Camerer CF, Babcock L, Loewenstein G, Thaler RH (1997) Labor Supply of New York City Babdrivers One Day at a Time. Q J Econ 112:407-441.

Carlsson F, Johansson-Stenman O (2012) Behavioral Economics and Environmental Policy. Annu Rev Resour Econ 4:75-99. doi: 10.1146/annurev-resource-110811-114547

Carson JM, McCullough KA, Pooser DM (2013) Deciding Whether to Invest in Mitigation Measures: Evidence From Florida. J Risk Insur 80:309-327. doi: 10.1111/j.1539-6975.2012.01484.x

Cato Institute (2012) ADDENDUM: Global Climate Change Impacts in the United States. Washington, USA

Creyer EH, Ross Jr WT (1997) The influence of firm behavior on purchase intention: do consumers really care about business ethics? J Consum Mark 14:421-432.

DellaVigna S (2009) Psychology and Economics: Evidence from the Field. J Econ Lit 47:315-372.

Doswald N, Osti M (2011) Ecosystem-based approaches to adaptation and mitigation - good practice examples and lessons learned in Europe. 
Eisenack K, Stecker R (2012) A framework for analyzing climate change adaptations as actions. Mitig Adapt Strateg Glob Chang 17:243-260. doi: 10.1007/s11027-011-9323-9

Fanis M (2004) Collective Action Meets Prospect Theory: An Application to Coalition Building in Chile, 1973 - 75. Polit Psychol 25:363-388.

Farber BHS (2008) Reference-Dependent Preferences and Labor Supply: The Case of New York City Taxi Drivers. Am Econ Rev 98:1069-1082.

Fiegenbaum A (1990) Prospect Theory and the Risk-Return Association - An Empirical Examination in 85 industries. J Econ Behav Organ 14:187-203.

Gawel E, Heuson C, Lehmann P (2012) Drivers of and barriers to public adaptation to climate change - An investigation of drivers and barriers from a Public Choice perspective.

Gowdy JM (2008) Behavioral economics and climate change policy. J Econ Behav Organ 68:632-644. doi: $10.1016 /$ j.jebo.2008.06.011

Greenpeace International (2013) Impacts. http://www.greenpeace.org/international/en/campaigns/climate-change/impacts/. Accessed 25 Apr 2013

Grothmann T, Reusswig F (2006) People at Risk of Flooding: Why Some Residents Take Precautionary Action While Others Do Not. Nat Hazards 38:101-120. doi: 10.1007/s11069-005-8604-6

Gsottbauer E, van den Bergh JCJM (2010) Environmental Policy Theory Given Bounded Rationality and Other-regarding Preferences. Environ Resour Econ 49:263-304. doi: 10.1007/s10640-0109433-y

Hallegatte S (2013) An exploration of the link between development, economic growth, and natural risk.

Hallegatte S, Hourcade J-C, Ambrosi P (2007) Using Climate Analogues for Assessing Climate Change Economic Impacts in Urban Areas. Clim Change 82:47-60. doi: 10.1007/s10584-006-9161-z

Harless DW, Camerer CF (1994) The Predictive Utility of Generalized Expected Utility Theories. Econometrica 62:1251-1289.

Harrison GW, Rutstro EE (2008) Risk Aversion in the Laboratory. Res Exp Econ 12:41-196. doi: 10.1016/S0193-2306(08)00003-3

Harrison GW, Rutström EE (2009) Expected utility theory and prospect theory: one wedding and a decent funeral. Exp Econ 12:133-158. doi: 10.1007/s10683-008-9203-7

Heath C, Larrick RP, Wu G (1999) Goals as Reference Points. Cogn Psychol 38:79-109.

Hershey JC, Schoemaker PJH (1985) Probability Versus Certainty Equivalence Methods in Utility Measurement: Are they Equivalent? Manage Sci 31:1213-1231. doi: 10.1287/mnsc.31.10.1213

Herweijer C, Ranger N, Ward RET (2009) Adaptation to Climate Change: Threats and Opportunities for the Insurance Industry. Geneva Pap Risk Insur 34:360-380. doi: 10.1057/gpp.2009.13 
Hey JD, Orme C (1994) Investigating Generalizations of Expected Utility Theory Using Experimental Data. Econometrica 62:1291-1326.

Hochrainer S, Mechler R, Pflug G (2009) Climate change and financial adaptation in Africa. Investigating the impact of climate change on the robustness of index-based microinsurance in Malawi. Mitig Adapt Strateg Glob Chang 14:231-250. doi: 10.1007/s11027-008-9162-5

Hulme M, Dessai S, Lorenzoni I, Nelson DR (2009) Unstable climates: Exploring the statistical and social constructions of "normal" climate. Geoforum 40:197-206.

IPCC (2013) Climate Change 2013: The Physical Science Basis Summary for Policymakers.

IPCC (2007a) Climate Change 2007: Mitigation. Cambridge University Press, Cambridge

IPCC (2007b) Climate Change 2007: Impacts, Adaptation and Vulnerability. Cambridge University Press, Cambridge

Iturbe-Ormaetxe I, Ponti G, Tomás J, Ubeda L (2011) Framing effects in public goods: Prospect Theory and experimental evidence. Games Econ Behav 72:439-447. doi: 10.1016/j.geb.2010.10.004

Kahneman D, Knetsch JL, Thaler RH (1990) Experimental Tests of the Endowment Effect and the Coase Theorem. J Polit Econ 98:1325-1348.

Kahneman D, Tversky A (1979) Prospect Theory: An Analysis of Decision under Risk. Econometrica 47:263-291.

Klein RJTT, Nicholls RJ, Ragoonaden S, et al. (2001) Technological Options for Adaptation to Climate Change in Coastal Zones. J Coast Res 17:531-543.

Knetsch JL (2010) Values of Gains and Losses: Reference States and Choice of Measure. Environ Resour Econ 46:179-188. doi: 10.1007/s10640-010-9355-8

Köszegi B, Rabin M (2007) Reference-Dependent Risk Attitudes. Am Econ Rev 97:1047-1073.

Köszegi B, Rabin M (2006) A Model of Reference-Dependent Preferences. Q J Econ 121:1133-1166.

Kundzewicz ZW (2002) Non-structural Flood Protection and Sustainability. Water Int 27:3-13.

Kunreuther H (1984) Causes of Underinsurance against Natural Disasters. Geneva Pap Risk Insur 9:206-220.

Kunreuther H, Heal G, Allen M, et al. (2013a) Risk management and climate change. Nat Clim Chang. doi: $10.1038 /$ NCLIMATE1740

Kunreuther HC, Ginsberg R, Miller L, et al. (1978) Disaster Insurance Protection: Public Policy Lessons. John Wiley and Co., New York, USA

Kunreuther HC, Pauly M V., McMorrow S (2013b) Insurance and Behavioral Economics. Cambridge University Press, Ney York, USA

Levy JS (2003) Applications of Prospect Theory to Political Science. Synthese 135:215-241. doi: 10.1023/A:1023413007698 
Levy JS (1996) Loss Aversion, Framing, and Bargaining: The Implications of Prospect Theory for International Conflict. Int Polit Sci Rev 17:179-195. doi: 10.1177/019251296017002004

Levy M, Levy H (2002) Prospect Theory: Much Ado about Nothing. Manage Sci 48:1334-1349.

Linnerooth-Bayer J, Mechler R (2006) Insurance for assisting adaptation to climate change in developing countries: a proposed strategy. Clim Policy 6:1.

Lockwood M (2011) Does the framing of climate policies make a difference to public support? Evidence from UK marginal constituencies. Clim Policy 11:1097-1112. doi: 10.1080/14693062.2011.579301

Mas A (2006) Pay, Reference Points, and Police Performance. Q J Econ 121:783-821.

Masters D (2004) Support and Nonsupport for Nationalist Rebellion: A Prospect Theory Approach. Polit Psychol 25:703-726.

McCaffery EJ, Slemrod J (2004) Toward an Agenda for Behavioral Public Finance.

Mercer J (2005) Prospect Theory and Political Science. Annu Rev Polit Sci 8:1-21. doi: 10.1146/annurev.polisci.8.082103.104911

Meyer V, Priest S, Kuhlicke C (2012) Economic evaluation of structural and non-structural flood risk management measures: examples from the Mulde River. Nat Hazards 62:301-324. doi: 10.1007/s11069-011-9997-z

Millner A, Dietz S, Heal G (2013) Scientific ambiguity and climate policy. Environ Resour Econ 55:2146.

Osberghaus D, Schwirplies C, Ziegler A (2013) Klimawandel in Deutschland: Risikowahrnehmung, Wissensstand und Anpassung in privaten Haushalten. Mannheim, Germany

Pramova E, Locatelli B, Brockhaus M, Fohlmeister S (2012) Ecosystem services in the National Adaptation Programmes of Action. Clim Policy 12:393-409. doi: 10.1080/14693062.2011.647848

Raschky PA, Weck-Hannemann H (2007) Charity hazard-A real hazard to natural disaster insurance? Environ Hazards 7:321-329. doi: 10.1016/j.envhaz.2007.09.002

Regierungskommission Klimaschutz (2012) Empfehlungen für eine niedersächsische Strategie zur Anpassung an die Folgen des Klimawandels. Hannover, Germany

Rieger MO, Wang M, Hens T (2011) Prospect Theory around the World.

Rosenman R, Fort R, Budd W (1988) Perceptions, fear, and economic loss: an application of prospect theory to environmental decision making. Policy Sci 21:327-350.

Schmidt U (2012) Insurance Demand under Prospect Theory: A Graphical Analysis.

Schwarze R, Schwindt M, Weck-Hannemann H, et al. (2011) Natural Hazard Insurance in Europe: Tailored Responses to Climate Change are Needed. Environ Policy Gouv 21:14-30. doi: 10.1002/eet 
Shogren JF, Parkhurst GM, Banerjee P (2010) Two Cheers and a Qualm for Behavioral Environmental Economics. Environ Resour Econ 46:235-247. doi: 10.1007/s10640-010-9376-3

Shogren JF, Taylor LO (2008) On Behavioral-Environmental Economics. Rev Environ Econ Policy 2:2644. doi: $10.1093 /$ reep/rem027

Sonnemans J, Schram A, Offerman T (1998) Public good provision and public bad prevention: The effect of framing. J Econ Behav Organ 34:143-161. doi: 10.1016/S0167-2681(97)00042-5

Stewart RE, Stewart BD (2001) The Loss of the Certainty Effect. Risk Manag Insur Rev 4:29-49.

Sydnor J, Dellavigna S, Segal U (2010) (Over)insuring Modest Risks. Am Econ J Appl Econ 2:177-199.

Tversky A, Kahneman D (1986) Rational Choice and the Framing of Decisions Rational Choice and the Framing of Decisions *. J Bus 59:251-278.

Tversky A, Kahneman D (1992) Advances in Prospect Theory: Cumulative Representation of Uncertainty. J Risk Uncertain 5:297-323.

Tversky A, Kahneman D (1981) The framing of decisions and the psychology of choice. Science (80- ) 211:453-458.

UNFCCC (2007) Investment and Financial Flows to Adress Climate Change.

Venkatachalam L (2008) Behavioral economics for environmental policy. Ecol Econ 67:640-645. doi: 10.1016/j.ecolecon.2008.01.018

Vis B (2011) Prospect Theory and Political Decision Making. Polit Stud Rev 9:334-343.

Wakker PP, Thaler RH, Tversky A (1997) Probabilistic Insurance. J Risk Uncertain 28:7-28.

Weisner E, Schernewski G (2013) Adaptation to climate change: A combined coastal protection and re-alignment scheme in a Baltic tourism region. J Coast Res 1963-1968. doi: 10.2112/SI65-333.1

Yohe G, Knee K, Kirshen P (2011) On the economics of coastal adaptation solutions in an uncertain world. Clim Change 106:71-92. doi: 10.1007/s10584-010-9997-0

\section{Appendix: Adaptation to Gains vs. Adaptation to Losses}

As to the best of the author's knowledge, there is yet no study dealing with the trade-off between alternative adaptation measures if one measure is to reduce climate damage, while the other is designed to exploit potential benefits. PT suggests that under specific conditions the former is preferred over the latter if EUT suggests indifference. This is shown by the following stylised example.

Assumptions: A farmer grows two crops, $\operatorname{crop} A$ and $B$ with the initial yields $a_{0}$ and $b_{0}$, respectively. Climate change decreases $a_{0}$ by $d_{A}$ unless adaptation is done. Adaptation costs $C_{A}$ can fully and immediately offset $d_{A}$. Similarly, climate change increases $b_{0}$ by $d_{B}$ if and only if adaptation is done, which costs $C_{B}$. Due to a limited budget, the farmer has to decide between adaptation in crop $A$ or $B$. 
For sake of simplicity and to concentrate on the role of the reference point, assume $d_{A}=d_{B}>C_{A}=$ $C_{B}>0$. All monetary outcomes are transferred to values by a PT-type value function $v($.$) with the$ usual properties of diminishing sensitivity and higher sensitivity for losses (i.e. $v(x)\langle-v(-x), x\rangle$ 0 ). It is further assumed that the yields of the two crops are evaluated separately - which is plausible if the crops are yielded at different points in time. Now define two possible reference points, namely the status quo and the situation expected under climate change, as outlined in Table 3.

Table 3: Implications of the reference point on evaluations of different riskless adaptation measures

\begin{tabular}{|l|c|c|}
\hline & $\begin{array}{l}\text { Reference point: } \\
\text { Current yield situation without } \\
\text { adaptation (status quo })\left(\boldsymbol{a}_{\mathbf{0}}+\boldsymbol{b}_{\mathbf{0}}\right)\end{array}$ & $\begin{array}{l}\text { Reference point: } \\
\text { Future yield situation without } \\
\text { adaptation }\left(\boldsymbol{a}_{\mathbf{0}}-\boldsymbol{\partial a}+\boldsymbol{b}_{\mathbf{0}}\right)\end{array}$ \\
\hline $\begin{array}{l}\text { Value of alternative (a) } \\
\text { (adaptation in crop } A \text { and } \\
\text { no adaptation in crop } B \text { ) }\end{array}$ & $v\left(-d_{A}+d_{A}-C_{A}\right)+v(0)$ \\
\hline $\begin{array}{l}\text { Value of alternative (b) } \\
\text { (adaptation in crop } B \text { and } \\
\text { no adaptation in crop } A \text { ) }\end{array}$ & $v\left(-d_{A}\right)+v\left(d_{B}-C_{B}\right)$ & $v(0)+v\left(d_{B}-C_{B}\right)$ \\
\hline Preferred alternative & $\begin{array}{l}\text { Preferences depend on } \\
\text { parameterisation of value function } \\
\text {-no clear tendency. }\end{array}$ & $\begin{array}{l}\text { Indifference between alternatives } \\
\text { (a) and (b). }\end{array}$ \\
\hline
\end{tabular}

The statement that if the current situation is the reference point no clear tendency is implied can be derived from the following. Alternative (a) is preferred over alternative (b) if and only if:

$$
v\left(-d_{A}+d_{A}-C_{A}\right)+v(0)>v\left(-d_{A}\right)+v\left(d_{B}-C_{B}\right)
$$

Simplifications and the definitions $d_{A}=d_{B}$ and $C_{A}=C_{B}$ yield

$$
-v\left(-d_{A}\right)+v\left(-C_{A}\right)>v\left(d_{A}-C_{A}\right)
$$

Now let us introduce a loss aversion parameter $\gamma$ which converts values of a negative outcome to negative values of the respective positive outcome:

$$
v(-x)=\gamma *-v(x), x>0
$$

Then, the inequality becomes

$$
\gamma\left(v\left(d_{A}\right)-v\left(C_{A}\right)\right)>v\left(d_{A}-C_{A}\right)
$$

Loss aversion $(\gamma>1)$ leads to the tendency that the inequality holds, and alternative (a) is preferred over alternative (b). However, due to diminishing sensitivity of the value function the following equation holds:

$$
v\left(d_{A}\right)-v\left(C_{A}\right)<v\left(d_{A}-C_{A}\right)
$$

This leads to the contrary tendency. Hence, without a specific parameterisation a general tendency cannot be derived for the first case in Table 3. The preferences depend on the concrete outcomes, the loss aversion parameter and the diminishing sensitivity parameters of the value function.

We can, however, use the parameters proposed by Tversky and Kahneman: $\gamma=2.25$, and $v(x)=x^{0.88}$. If we further assume that the costs of adaptation are defined as a fixed share $m$ of adaptation benefits $\left(C_{A}=m * d_{A}, 0<m<1\right)$, the inequality becomes 


$$
2.25 *\left(\left(d_{A}\right)^{0.88}-\left(m * d_{A}\right)^{0.88}\right)>\left(d_{A}-m * d_{A}\right)^{0.88}
$$

And after simplification:

$$
2.25 *\left(1-m^{0.88}\right)>(1-m)^{0.88}
$$

Which holds for $m<0.9966$ (approximately). Hence, in the case that adaptation costs are substantially lower than benefits and under the parameterisation of Tversky and Kahneman, the loss aversion effect dominates the diminishing sensitivity effect, and an adaptation measure (a) avoiding losses is preferred over a comparable measure (b) which yields benefits. 